\title{
Assessing the home eating context and fruit and vegetable consumption in children: new methods from the UK National Diet and Nutrition Survey (2008-2010)
}

\author{
T. N. Mak ${ }^{1}$, C. J. Prynne ${ }^{1}$, D. Cole ${ }^{1}$, E. Fitt ${ }^{1}$, C. Roberts ${ }^{2}$, B. Bates ${ }^{2}$, A. M. Stephen ${ }^{1}$ \\ ${ }^{1}$ MRC Human Nutrition Research, Elsie Widdowson Laboratory, 120 Fulbourn Road, CB1 9NL Cambridge, UK and \\ ${ }^{2}$ National Centre for Social Research, 35 Northampton Square, London ECIV OAX, UK
}

There is currently limited knowledge on the associations between eating context in relation to food consumption in children at the population level. The eating context describes the location, the people eating with and other environment influences such as television at an eating occasion. Children spend the majority of their eating occasions at home, and by studying the eating context within home will allow us to determine the contextual factors that drive positive eating behaviours in children. The aim of this study is to present a methodology to quantify the home eating contexts and to identify associations with fruit and vegetable consumption in UK children.

The National Diet and Nutrition Survey (NDNS) Rolling Programme has introduced a new feature in the 4 day food diaries, which asked participants to record four elements of their eating context, including where and with whom the meal was consumed, whether the TV was on and if eaten at a table, as well as detailed dietary information for each eating occasion ${ }^{(1)}$. Data was collected for 642 children aged 1.5-10 y in the first two years of NDNS (2008-2010). Eating occasions that took place within home were included in the analyses $(n=12020)$; total fruit and vegetable consumption was disaggregated and calculated for each eating occasion. Mixed-effects logistic regression and multilevel multinomial logistic regression were used. All models were adjusted for age, sex, time of meal, weekend/ weekday variation.

Children were less likely to consume vegetables in the kitchen $(\mathrm{OR}=0.55)$, living room $(\mathrm{OR}=0.17)$ and other areas within home $(\mathrm{OR}=0.11)$ than compared to eating in the dining room. The likelihood of consuming $>60 \mathrm{~g}$ vegetables were around $50 \%$ lower in the living room $(p<0.001)$ than the dining room. They were approximately two times more likely to consume $>50-100 \mathrm{~g}$ of fruit in the kitchen, living room and other areas than the dining room (all $p<0.001$ ). Compared to eating with parents only, children were more likely to eat vegetables with parents and siblings $(\mathrm{OR}=1.22)$ and with adult relatives and friends $(\mathrm{OR}=1.58)$; least likely when alone or with others $(\mathrm{OR}=0.33)$. Children were more likely to eat vegetables when the TV was off $(\mathrm{OR}=1.75)$; and they had higher odds of consuming $>100 \mathrm{~g}$ of vegetable $(\mathrm{OR}=1.54)$ but lower odds of eating $>100 \mathrm{~g}$ of fruit $(\mathrm{OR}=0.69)$ when TV was off. Children were $90 \%$ less likely to eat vegetable when not eating at table $(p<0.001)$. However, they were more likely to consume $>50 \mathrm{~g}$ of fruit when not eating at the table (all $p<0.01$ ).

For the first time we quantitatively studied the home eating context in relation to fruit and vegetable consumption in a nationally representative sample of children using food diaries. Our results suggest that eating in the dining room at the table and with the TV off may be beneficial to children's vegetable consumption. This serves as a good guidance for parents and carers to provide a positive eating context for their children. The eating context assessment method can be a simple addition to current dietary assessment tools to enable further understanding of eating behaviours and consumption of different food groups.

NDNS is funded by Department of Health and Food Standards Agency (MCR Project No. MC_US_A090_0039).

1. Department of Health, Food Standards Agency. National Diet and Nutrition Survey: Headline results from Years 1 and 2 (combined) of the rolling programme 2008/9-2009/10. 2011 [updated 27th October 2011]; Available from: http://www.dh.gov.uk/prod_consum_dh/groups/dh_digitalassets/ documents/digitalasset/dh_128550.pdf 